\title{
The Simple Economics of Conservation Clubs
}

\author{
Arthur J. Caplan ${ }^{1}$ \\ ${ }^{1}$ Department of Applied Economics, Utah State University, Logan, Utah, USA \\ Correspondence: Arthur J. Caplan, Department of Applied Economics, Utah State University, Logan, Utah, USA. \\ Tel: 1-435-797-0775. E-mail: arthur.caplan@usu.edu
}

Received: May 4, 2017

Accepted: May 18, 2017

Online Published: May 31, 2017

doi:10.5539/enrr.v7n2p112

URL: https://doi.org/10.5539/enrr.v7n2p112

The research is financed by the Utah State University Seed Program to Advance Research Collaborations (SPARC) and the Utah Agricultural Experiment Station (UAES Grant number 1074)

\begin{abstract}
This paper examines how a regulatory authority might ideally promote the formation of "conservation clubs" among households in order to initiate and empower voluntary household-level water and energy conservation efforts. We characterize a socially optimal conservation benchmark and derive the conditions necessary for a club to effectively attain this benchmark on behalf of the wider community. Both theoretical and numerical analyses are used to demonstrate ways in which households choose to become club members and are subsequently empowered to undertake conservation efforts. The avenues through which club membership might empower households include (1) information provision/education that is assumed to alter key parameters of the household's welfare function, thereby inducing the household to build a stronger "conservation ethic," and (2) bulk-pricing arrangements that reduce the prices of applicable conservation technologies. Our results highlight key relationships between the regulator and households, as well as between the club and the marketplace, that should be measured empirically before efforts are made to establish conservation clubs in practice.
\end{abstract}

Keywords: conservation, club, conservation ethic, bulk-pricing

\section{Introduction}

If the effects of government-initiated price and non-price changes on voluntary household conservation efforts have revealed anything at all during the past four decades, it would be the absence of a proverbial silver bullet (Note 1). For instance, water conservation studies generally find that public education campaigns result in small, temporary reductions in demand (Billing and Day, 1989; Nieswiadomy, 1992; Baumann et al., 1998; USEPA, 1998; Wang et al., 1999; Renwick and Green, 2000; Howarth and Butler, 2004) (Note 2). Household metering (e.g., use of "smart meters" that enable households to conveniently monitor their real-time water usage) can have a significant, albeit temporary, negative impact on outdoor watering demand. However, the effect on indoor demand is significantly less (Linaweaver et al., 1966 and Maddaus, 2001) (Note 3). And although retrofitting indoor and outdoor appliances and technologies has the ability to significantly reduce water consumption on a household-byhousehold basis (Mayer et al., 2000, 2003, and 2004; Mohadjer and Rice, 2004; Turner et al., 2004), few studies have been able to quantify the effects of subsidy/rebate programs in spurring their adoption by households (Note 4). Estimates of price elasticity, which generally reveal outdoor and indoor household demand to be price inelastic and lacking in persistence, are similarly hindered by a paucity of studies based on price ranges wide enough to reflect the true potential of pricing policies to induce conservation effort (Note 5). In concert with this empirical evidence, water utilities have, as Pint (1999) points out, "traditionally been reluctant to use price to allocate water supplies, even in periods of drought,......[relying instead] on preachment and exhortation to induce conservation, and if necessary, mandatory quantity and use restrictions."

As a result of water utility inertia and the absence of any silver bullet for local governments, the need for novel approaches to motivate voluntary household-level water and energy conservation is readily apparent. This paper explores one such approach - the formation of conservation clubs. By "conservation clubs" we have in mind the type of club originally envisioned by Olson (1965), where an (inclusive) group of agents exploits economies of scale and shares in the production and consumption of a public good without restrictions on membership size. 
In our case, the club produces the public good not only for its members, but also for the community at large (Note 6).

A club of this kind might evolve according to the following (admittedly ideal) scenario. A coordinator (whose salary and program budget are initially government-funded) recruits households into the club according to a predetermined fee schedule (e.g., a fixed annual fee). Fee revenues then fund the coordinator's continuing salary and program budget. Member households gain access to information/education and reduced prices for more efficient appliances and technologies (Note 7). The effect of information/education amplifies through social networks that form among club members (Note 8). The club's bulk-pricing arrangements initiate a 'virtuous cycle' in retail markets, whereby the club's bulk orders ultimately encourage local merchants to "rotate" the more efficient appliances and technologies into their standing inventories, thus increasing their availability to the general public as well. In essence, the club approach to conservation targets households with stronger predispositions toward conservation (these types of households would presumably be more likely to self-select into the club) and thus with higher probabilities of implementing more pronounced conservation measures than what might be attainable through traditional government-sponsored programs, e.g., through blanket public awareness campaigns and rebate programs (Note 9). A simple schematic of how a conservation club evolves is depicted in Figure 1.

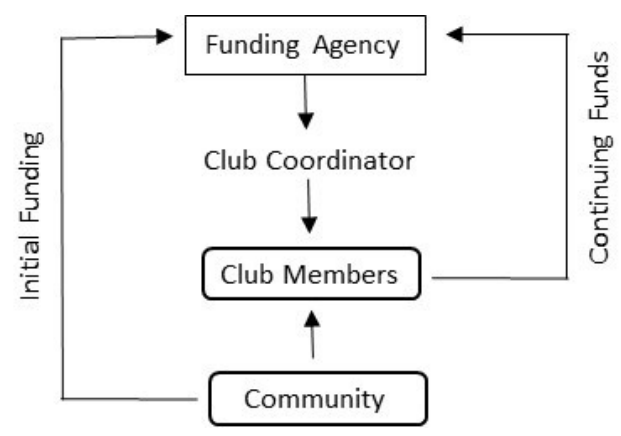

Figure 1. Evolution of a conservation club.

In this paper we focus attention on two overriding issues of club formation and function: (1) how households determine whether to join the club, and (2) conditions that must be satisfied in order for the club to effectively attain a socially efficient level of aggregate conservation effort on behalf of the wider community of households (Note 10). Toward these ends, we lay out in Section 2 a basic theory of conservation clubs, beginning with a description of the household and the establishment of a Pareto-efficient benchmark. The conditions necessary for a club to attain this benchmark on behalf of the wider community are also derived. Section 3 then numerically solves a simple version of the theoretical model in order to better understand - in a qualitative sense - the extent of the changes necessary (both in terms of price reductions and the effects of information provision/education) for club members to achieve the socially optimal conservation level. Section 4 summarizes the paper's main findings, discusses its limitations, and offers avenues for future research.

\section{A Simple Theory of Conservation Clubs}

\subsection{The Basic Model}

Assume household $i, i=1, \ldots N$, chooses numeraire good $x_{i}$ and a flow of conservation $y_{i}$ (through its "conservation effort" level) to maximize continuous, strictly quasi-concave household utility function $u_{i}\left(x_{i}, y_{i} ; \alpha_{i}, \beta_{i}, \gamma_{i}, \theta\right)$ subject to budget constraint $x_{i}+p_{i} y_{i} \leq m_{i}$, where parameter $\alpha_{i}$ ensures $\partial u_{i} / \partial x_{i}>0$ and $\partial^{2} u_{i} / \partial x_{i}^{2}<0$, and parameter $\beta_{i}$ ensures $\partial u_{i} / \partial y_{i} \geq 0$ and $\partial^{2} u_{i} / \partial y_{i}^{2} \leq 0$ (Note 11). Parameter $\theta$ represents the regulator-announced expected capacity gap, or probability of a community-wide water shortage during a given period, or season (with $\gamma_{i}$ ensuring $\left.\partial u_{i} / \partial \theta<0\right)$ (Note 12). For the purposes of this model, we therefore assume $\theta$ is the water-shortage equivalent of a common weather report. Households believe the report is as accurate as possible given society's current state of knowledge, and therefore have no incentive to derive their own subjective probability distributions over the capacity gap. Parameter $p_{i}$ is the household-specific, per-unit net price of $y_{i}$, and $m_{i}$ is household $i$ 's (fixed) level of wealth (Note 13, 14).

For simplicity, we assume $y_{i}$ is a composite conservation flow with a single corresponding net price, $p_{i}$. In reality, 
$y_{i}$ is a vector of separate flows resulting from different goods and effort levels. For example, the respective flows of water savings derived from the installation of water-efficient appliances and technologies, each with their own associated household-specific, per-unit net price premiums, results in one set of conservation flows. The price premium (imputed to $p_{i}$ ) represents the increment paid for the water-efficient appliance/technology above the price of its alternative conventional appliance/technology, net of any pro-rated cost savings associated with the wateruse savings induced by use of the water-efficient appliance/technology. Manual and intellectual effort spent by the household conserving water through researching and installing a conservation good (which, by itself, could affect utility either positively or negatively) represents another type of flow (in this case obtained through the consumption of time), with the household's opportunity wage acting as the corresponding household-specific price (again imputed to $p_{i}$ ). For ease of exposition, and without loss of generality for the purpose at hand, we condense these separate flows into a single, composite flow and assume that increases in this flow do not decrease household utility. We similarly condense the corresponding net prices associated with each of the conservation flows into a single household-specific price variable and assume its net value is positive for each household.

As a result of the previously mentioned curvature conditions on $u_{i}$, the first-order conditions for household $i$ 's utility maximization problem can be written as (Note 15),

$$
\begin{gathered}
\frac{\partial u_{i}}{\partial y_{i}} \frac{\partial u_{i}}{\partial x_{i}} \leq p_{i}, \quad i=1, \ldots, N \\
m_{i}=x_{i}+p_{i} y_{i}, \quad i=1, \ldots, N
\end{gathered}
$$

where conditions (1) hold with equality(inequality) for $y_{i}>0\left(y_{i}=0\right), i=1, \ldots, N$. Conditions (1) are standard Kuhn-Tucker tangency conditions, where $x_{i}>0$ and $y_{i} \geq 0$ are chosen such that (private) marginal rate of substitution does not exceed the price ratio. Further, conditions (1) and (2) can be solved simultaneously to obtain demand functions $x_{i}^{*}=x_{i}\left(\theta, p_{i}, m_{i}, \alpha_{i}, \beta_{i}, \gamma_{i}\right)$ and $y_{i}^{*}=y_{i}\left(\theta, p_{i}, m_{i}, \alpha_{i}, \beta_{i}, \gamma_{i}\right)$. For future reference we denote household $i$ 's indirect utility function as $u_{i}\left(x_{i}^{*}, y_{i}^{*} ; \theta\right)=v_{i}\left(\theta, p_{i}, m_{i}, \alpha_{i}, \beta_{i}, \gamma_{i}\right)$, which, once inverted with respect to $m_{i}$, results in expenditure function $e_{i}\left(\theta, p_{i}, \alpha_{i}, \beta_{i}, \gamma_{i}, v_{i}^{0}\right)$, where $v_{i}^{0}$ is a reference utility level (usually taken to be the status quo level). The household's compensating-variation (or willingess-to-pay) function for club membership is then defined as $W T P_{i}=m_{i}-e_{i}\left(\theta^{\prime}, p_{i}^{\prime}, \alpha_{i}, \beta_{i}, \gamma_{i}, v_{i}^{0}\right)$, where $\theta^{\prime}$ and $p_{i}^{\prime}$ are new parameter values the household attains - and is willing to pay for - through club membership (Note 16). Standard comparative static effects generally hold for $W T P_{i}$, i.e., $\partial W T P_{i} / \partial \theta \leq 0$, and $\partial W T P_{i} / \partial p_{i} \leq 0$. Lastly, letting $F$ represent the fixed membership fee, household $i$ chooses to join the conservation club as long as (Note 17).

$$
W T P_{i} \geq F, \quad i=1, \ldots, N
$$

In other words, the household joins the club as long as the total value gained through membership is no less than the cost of joining (Note 18).

\subsection{A Pareto Efficient Benchmark}

A Pareto efficient benchmark can be determined as the solution (for $i=1, \ldots, N$ ) to a benevolent social planner's problem (Note 19),

$$
\begin{aligned}
\max _{x_{i}, y_{i}} & \sum_{i=1}^{N} u_{i}\left(x_{i}, y_{i}, \theta\left(\sum_{i=1}^{N} y_{i}\right) ; \alpha_{i}, \beta_{i}, \gamma_{i}\right) \\
\text { subject to } & \sum_{i=1}^{N} m_{i} \geq \sum_{i=1}^{N}\left(x_{i}+p_{i} y_{i}\right)
\end{aligned}
$$

which results in the first-order conditions

$$
\frac{\frac{\partial u_{i}}{\partial y_{i}}+\sum_{j=1}^{N}\left(\frac{\partial u_{j}}{\partial \theta} \frac{\partial \theta}{\partial y_{i}}\right)}{\frac{\partial u_{i}}{\partial x_{i}}} \leq p_{i}, \quad i, j=1, \ldots, N
$$




$$
\sum_{i=1}^{N} m_{i}=\sum_{i=1}^{N}\left(x_{i}+p_{i} y_{i}\right) .
$$

The key difference between the individual-households' and social planner's problems - aside from the aggregation of household utilities and budget constraints occurring in the latter problem - is an explicit recognition by the social planner that $\theta$ is a function of the community's aggregate conservation flow rather than an exogenous parameter. As a result, conditions (4) incorporate the value (aggregated over all households) of an additional unit of conservation flow in terms of how it reduces the community's capacity gap (i.e., the positive externality associated with an increase in a given household's conservation flow), unlike conditions (1) (Note 20). This value, represented by the left-hand-side term $\sum_{j=1}^{N}\left(\frac{\partial u_{j}}{\partial \theta} \frac{\partial \theta}{\partial y_{i}}\right) / \frac{\partial u_{i}}{\partial x_{i}}>0$ in (4), leads to the following results: $x_{i}^{* *} \leq x_{i}^{*}$ and $y_{i}^{* *} \geq y_{i}^{*}$ for $i=1, \ldots, N$, and $\theta^{* *} \leq \theta^{*}$ for given $p_{i}$, where the $* *$ superscript denotes solution values for the social planner's problem (Note 21). In other words, absent a mechanism that induces households to internalize the positive external effects of their respective conservation efforts (and assuming household preferences are such that the social planner chooses $y_{i}>0$ for at least one household) the community generally conserves too little and thus faces too high an expected capacity gap.

A traditional (Pigouvian) mechanism for this problem would be a set of household-specific subsidies for each household in the community that reduce the prices of $y_{i}$ (i.e., the $\left.p_{i}, i=1, \ldots, N\right)$ by the amounts $\sum_{j=1}^{N}\left(\frac{\partial u_{j}}{\partial \theta} \frac{\partial \theta}{\partial y_{i}}\right) / \frac{\partial u_{i}}{\partial x_{i}}$, $i, j=1, \ldots, N$, where variables $x_{i}, y_{i}$, and $\theta$ are evaluated at their respective $* *$ values. Another Pigouvian mechanism could be a set of taxes, $t_{x_{i}}$, on corresponding numeraire goods $x_{i}, i=1, \ldots, N$ which can be shown to satisfy

$$
t_{x_{i}}=\frac{\sum_{j=1}^{N}\left(\frac{\partial u_{j}}{\partial \theta} \frac{\partial \theta}{\partial y_{i}}\right)}{\frac{\partial u_{i}}{\partial y_{i}}} \quad i, j=1, \ldots, N
$$

where again the variables $x_{i}, y_{i}$, and $\theta$ are evaluated at their respective $* *$ values. It should be noted that these household-specific subsidy and tax mechanisms, which obtain not only $\theta^{* *}$, but also $x_{i}^{* *}$ and $y_{i}^{* *}$ for $i=1, \ldots, N$, suffer from the requirement that the regulator know individual household preferences. Also, depending upon the number of households in the community and their respective marginal values of reducing the expected capacity gap, the tax and subsidy rates could be excessively large in practice, resulting in either untenable tax burdens for households or subsidy burdens for the government, respectively. As pointed out by Pal and Saha (2014), however, a joint tax-subsidy scheme can conceivably be implemented that balances the government's budget (Note 22).

The possibility of these potential tax and subsidy burdens also provide some justification for our exploration of new approaches to what we now recognize as an externality problem in the context of the resource-conservation decision. As we demonstrate in Section 2.3, given adequate enough responses by club members (i.e., increases in their conservation effort) to the information/education and price subsidies "delivered" through membership, establishment of a conservation club can, under certain circumstances, result in the Pareto-efficient expected capacity gap (i.e., $\theta^{* *}$ ) without the need for household-specific taxes or subsidies. Doing so, however, requires that the club coordinator know how the member's conservation effort levels and membership size respond to these "deliverables," including how membership size responds to fee level. Similar to the Pigouvian tax and subsidy mechanisms, this knowledge in turn requires information about the preferences of member and (marginal) non-member households.

\subsection{Conservation Clubs}

Incorporating clubs into the framework developed above requires some additional definitions and assumptions that are consistent with the curvature conditions on $u_{i}, i=1, \ldots, N$, presented in Section 2.1. To begin, let $E_{r}$ represent the effort level undertaken by the club's coordinator to recruit new members, and $E_{m}$ represent the coordinator's effort to educate and inform members as well as to achieve reductions in the members' respective $p_{i}$ values, e.g., through bulk-pricing arrangements with retailers of efficient appliances and technologies (where the $m$ subscript on $E_{m}$ is meant to remind the reader of the coordinator's effort to motivate conservation among club members, and the $r$ subscript denotes the coordinator's effort to recruit new members). To account for the effects of the coordinator's effort to intensively educate and inform members (thereby leading the members to develop their respective "conservation ethics"), we assume that, by virtue of joining the club, (1) members' utility parameters $\alpha_{i}, \beta_{i}$, and $\gamma_{i}$ become functions of $E_{m}$, and (2) members learn the respective values of their own $\partial \theta / \partial y_{i}<0$ (rather than the full external effect associated with the choice of $y_{i}$, as in the social planner's problem) (Note 23).

With respect to the first assumption, we assume that $\partial \alpha_{i} / \partial E_{m}<0$ (members derive lower utility value from a given amount of $x_{i}$ as $E_{m}$ increases), $\partial \beta_{i} / \partial E_{m}>0$ (members derive greater utility value from a given amount of $y_{i}$ as $E_{m}$ 
increases), and $\partial \gamma_{i} / \partial E_{m}<0$ (members derive lower (negative) utility value from a given expected capacity gap $\theta$ as $E_{m}$ increases). In other words, an increase in $E_{m}$ is capable of strengthening a club member's conservation ethic by altering the household's utility parameters, and, with respect to the second assumption, by building its awareness of the effect its conservation effort has on the community's expected capacity gap. Similarly, to account for the coordinator's ability to achieve bulk-pricing arrangements for members we assume $\partial p_{i} / \partial E_{m}<0$ for all members $i$.

Membership size is represented by $n\left(E_{r}, F\right)$. If we classify all households in the community according to their willingness to pay for club membership (i.e., according to their $W T P_{i}$ derived in Section 2.1) and then rank them in descending order, $n\left(E_{r}, F\right)$ can also be interpreted as the marginal household, where $W T P_{n\left(E_{r}, F\right)}=F$ (for a large enough community of households). In other words, for given $E_{r}$ and $F$, households 1 to $n\left(E_{r}, F\right)$ join the club and households $n\left(E_{r}, F\right)+1$ to $N$ do not. Appealing to conditions (3), we see that, all else equal, $\partial n / \partial F<0$ (i.e., a higher fixed fee reduces the number of members). Further, $\partial n / \partial E_{r}>0$, since $\partial n / \partial E_{r} \leq 0$ implies budget imbalance in the coordinator's problem (discussed in more detail below). In this case, revenue from the membership fee would be non-increasing in coordinator effort, while corresponding costs would be increasing.

For future reference, we assume household preferences are such that $\partial^{2} n / \partial E_{r}{ }^{2}<0$ (i.e., diminishing returns to coordinator effort), $\partial^{2} n / \partial F^{2}<0$ (increasing costs associated with increases in the membership fee - in terms of reductions in membership size), and

$$
-\frac{\partial^{2} n}{\partial E_{r}{ }^{2}} \frac{\partial n}{\partial F}+2 \frac{\partial^{2} n}{\partial E_{r} \partial F} \frac{\partial n}{\partial E_{r}}-\frac{\frac{\partial^{2} n}{\partial F^{2}}\left(\frac{\partial n}{\partial E_{r}}\right)^{2}}{\frac{\partial n}{\partial F}}<0 .
$$

This last condition ensures concavity of the "membership isoquant" (discussed in more detail below) (Note 24).

The coordinator's problem can therefore be written as,

$$
\begin{array}{rl}
\min _{E_{r}, E_{m}, F} & C\left(E_{r}, E_{m}\right)+A \\
\text { subject to } & \theta(Y)=\theta^{* *} \\
& C\left(E_{r}, E_{m}\right)+A=n\left(E_{r}, F\right) F
\end{array}
$$

where $C\left(E_{r}, E_{m}\right)$ represents total variable cost associated with the coordinator's recruitment and motivation effort levels $\left(C(\cdot)\right.$ is assumed increasing and convex in $E_{r}$ and $\left.E_{m}\right), A$ represents total fixed cost, and $Y=\sum_{i=1}^{n\left(E_{r}, F\right)} y_{i}^{*}\left(E_{m}\right)+$ $\sum_{i=n\left(E_{r}, F\right)+1}^{N} y_{i}{ }^{*}$. The first constraint acknowledges that the coordinator's goal in choosing $E_{r}, E_{m}$, and $F$ is to obtain the socially efficient capacity gap. The second constraint is budget balance (Note 25).

The $y_{i}{ }^{*}\left(E_{m}\right)$ term in $\sum_{i=1}^{n\left(E_{r}, F\right)} y_{i}{ }^{*}\left(E_{m}\right)$ accounts for the fact that the optimized conservation demands of households included in the club (i.e., households $i=1, \ldots, n\left(E_{r}, F\right)$ ) are now each functions of $E_{m}$; functions which in turn are known (or learned) by the coordinator (Note 26). For example, by knowing/learning the $\partial \alpha_{i} / \partial E_{m}, \partial \beta_{i} / \partial E_{m}$, $\partial \gamma_{i} / \partial E_{m}$, and $\partial p_{i} / \partial E_{m}$ terms mentioned above for $i=1, \ldots, n\left(E_{r}, F\right)$, and by then solving member $i$ 's decision problem presented in Section 2.1, the coordinator is able to determine the $y_{i}{ }^{*}\left(E_{m}\right)$ functions for households $i=$ $1, \ldots, n\left(E_{r}, F\right)$. The $y_{i}{ }^{*}$ terms in $\sum_{i=n\left(E_{r}, F\right)+1}^{N} y_{i}{ }^{*}$ are not directly functions of $E_{m}$ because these households $(i=$ $\left.n\left(E_{r}, F\right)+1, \ldots, N\right)$ do not become club members, and thus the coordinator must take their conservation flows as given.

By having to take non-member conservation flows as given, the coordinator is unable to use any of its policy variables $\left(E_{r}, E_{m}\right.$, and $\left.F\right)$ to directly control for potential free-riding behavior among non-member households in response to member-household conservation effort (i.e., control for "external free-riding"). The coordinator is, however, potentially able to internalize the incentives for free-riding among club members in response to nonmember-household conservation effort (i.e., control for "internal free riding") through the choice of $E_{m}$. External and internal free-riding will generally occur as the capacity gap falls in response to the club members' increased conservation efforts (Note 27). However, to the extent that the external free-riding effect is small enough in aggregate relative to the club members' collective response to the coordinator's $E_{m}$, scope will exist for the club's increased conservation effort to offset the consequences of external free-ridership in the course of the club's efforts to move the community toward the socially efficient capacity gap.

For example, in the event that household utility functions, $u_{i}(\cdot)$, are additively separable in $\theta$, the incentive for external free-riding in general will not be present due to the maintained assumption that non-member households take $\theta$ as given in their decision problems (Note 28). Further, to the extent that non-member households experience 
some warm glow effect from their private conservation efforts (i.e., $\partial u_{i} / \partial y_{i}>0$ for some or all of $i=n\left(E_{r}, F\right)+$ $1, \ldots, N)$, their incentive to free ride is at least partially offset by the decrease in utility they would experience as they reduce their conservation efforts (Note 29). To the extent that the club is unable to offset external free-ridership, an additional mechanism designed solely for non-members - for instance a targeted version of a tax or subsidy, as derived in Section 2.2 - would therefore need to be implemented jointly with the formation of the club.

The first-order optimality conditions for the club equilibrium (i.e., for the optimal choices of $E_{r}, E_{m}$, and $F$, respectively) are (Note 30$)$,

$$
\begin{gathered}
(1+\lambda) \frac{\partial n}{\partial E_{r}} F-\lambda \frac{\partial C}{\partial E_{r}}+\mu \frac{\partial \theta}{\partial Y} \frac{\partial n}{\partial E_{r}}\left(y_{n\left(E_{r}, F\right)}-y_{n\left(E_{r}, F\right)+1}\right)=0 \\
-\lambda \frac{\partial C}{\partial E_{m}}+\mu \frac{\partial \theta}{\partial Y} \sum_{i=1}^{n\left(E_{r}, F\right)} \frac{\partial y_{i}^{*}}{\partial E_{m}}=0 \\
(1+\lambda)\left(\frac{\partial n}{\partial F} F+n\left(E_{r}, F\right)\right)+\mu \frac{\partial \theta}{\partial Y} \frac{\partial n}{\partial F}\left(y_{n\left(E_{r}, F\right)}-y_{n\left(E_{r}, F\right)+1}\right)=0
\end{gathered}
$$

where $(1+\lambda)>0$ is the Lagrangian multiplier on the club's budget-balance constraint, $\mu<0$ is the multiplier on the capacity-gap constraint, and $\frac{\partial y_{i}{ }^{*}}{\partial E_{m}}, i=1, \ldots, n\left(E_{r}, F\right)$, represent the respective partial effects of $E_{m}$ on $y_{i}{ }^{*}, i=$ $1, \ldots, n\left(E_{r}, F\right)$ (Note 31). The first and third terms in condition (6) represent the marginal benefits associated with an incremental increase in the coordinator's recruitment effort, $E_{r}$. The first term is the marginal benefit of additional club revenue associated with the increase in club size (normalized by $\lambda$ ). The third term is the (social) marginal benefit of the incremental increase in conservation flow associated with an increase in club size (normalized by $\mu$ ). The second term in condition (6) is the marginal cost of additional coordinator recruitment effort (also normalized by $\lambda$ ). The first and second terms in condition (8), which correspond to the first and third terms in condition (8), respectively, have equivalent interpretations with respect to the coordinator's choice of the membership fee $F$ (Note 32). Similarly, the first and second terms in (7) represent the corresponding marginal cost and benefit, respectively, associated with the coordinator's choice of $E_{m}$.

These optimality conditions, along with the two constraints from the coordinator's problem, determine optimal (i.e., cost-minimizing) levels of coordinator effort, $E_{r}{ }^{c}$ and $E_{m}{ }^{c}$, an optimal membership fee, $F^{c}$, optimal conservation flows $y_{i}{ }^{c}=y_{i}{ }^{*}+\frac{\partial y_{i}{ }^{*}}{\partial E_{m}}$ for all club members $i=1, \ldots, n\left(E_{r}{ }^{c}, F^{c}\right)$, and, ultimately, an optimal expected capacity gap, $\theta^{c}=\theta^{* *} . E_{r}{ }^{c}$ and $F^{c}$ in turn determine optimal club size, $n^{c}=n\left(E_{r}{ }^{c}, F^{c}\right)$. Note that although the coordinator cannot directly choose non-member conservation flows $y_{i}$ (for households $i=n\left(E_{r}{ }^{c}, F^{c}\right)+1, \ldots, N$ ) in this problem, at an interior solution the coordinator nevertheless meets the capacity-gap constraint for the given set of $y_{i}, i=$ $n\left(E_{r}{ }^{c}, F^{c}\right)+1, \ldots, N$.

With this notation in hand, we can formally state the necessary and sufficient condition for club-member conservation effort to obtain the socially efficient capacity gap in the face of potential free ridership,

$$
\sum_{i=1}^{n^{c}} \frac{\partial y_{i}^{*}}{\partial E_{m}}-\sum_{i=n^{c}+1}^{N} \frac{\partial y_{i}^{*}}{\partial \theta} \sum_{i=1}^{n^{c}} \frac{\partial \theta}{\partial y_{i}^{*}} \frac{\partial y_{i}^{*}}{\partial E_{m}}=\sum_{i=1}^{N}\left(y_{i}^{* *}-y_{i}^{*}\right)
$$

where $\sum_{i=n^{c}+1}^{N} \frac{\partial y_{i}{ }^{*}}{\partial \theta} \sum_{i=1}^{n^{c}} \frac{\partial \theta}{\partial y_{i}{ }^{*}} \frac{\partial y_{i}{ }^{*}}{\partial E_{m}}>0$ implies external free-riding in the aggregate. We note that $y_{i}{ }^{c}$ in this context results directly from $E_{m}$ for club members $i=1, \ldots, n^{c}$, and indirectly through $E_{m}$ for non-members $i=$ $n^{c}+1, \ldots, N$, where "indirectly" in this case means the effect on $\theta$ brought about by changes in club-members' $y_{i}{ }^{*}$ in response to $E_{m}$. Condition (9) states that, for the case of potential external free-riding in the aggregate (i.e., $\left.\sum_{i=n^{c}+1}^{N} \frac{\partial y_{i}{ }^{*}}{\partial \theta} \sum_{i=1}^{n^{c}} \frac{\partial \theta}{\partial y_{i}{ }^{*}} \frac{\partial y_{i}{ }^{*}}{\partial E_{m}}>0\right)$, the total change in conservation flow among club members net of aggregate external free-riding must equal the difference between the socially efficient and competitive-equilibria aggregate conservation flows (reference Section 2.1 for the characterizations of these two equilibria). A technical appendix addresses the related issues of existence, uniqueness, and local stability of the model's conservation-club equilibrium.

Focusing now on the relationship between club size and the membership fee, we can combine conditions (6) and (8), resulting in, 


$$
-\frac{\frac{\partial n}{\partial E_{r}}}{\frac{\partial n}{\partial F}}=\frac{\lambda}{1+\lambda} \frac{\frac{\partial C}{\partial E_{r}}}{n\left(E_{r}, F\right)} .
$$

The left-hand side of (10) represents the coordinator's marginal benefit (measured in dollars per unit of coordinator recruitment effort) resulting from a (net) increase in membership size, while the right-hand side represents the marginal cost of coordinator recruitment effort (per club member). These results are depicted in Figure 2.

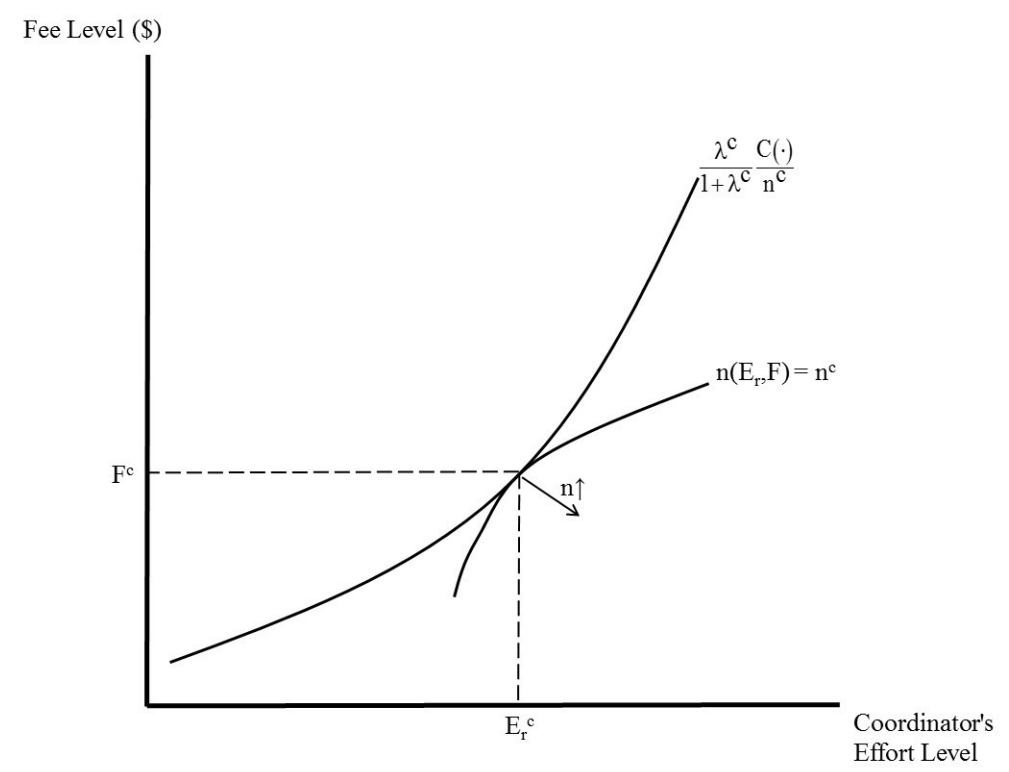

Figure 2. Determination of optimal club size in a club equilibrium

In Figure 2, the curve labeled $n\left(E_{r}, F\right)=n^{c}$ represents different combinations of $E_{r}$ and $F$ that result in membership level $n^{c}$, i.e. the curve is effectively a membership isoquant. Note that membership isoquants located further to the southeast are defined over larger membership sizes. The isoquants are upward-sloping and concave as a result of the previously mentioned curvature conditions on $n\left(E_{r}, F\right)$. The curve labeled $(\lambda /(1+\lambda))(C(\cdot) / n(\cdot))$ represents the shadow-value-adjusted total cost of coordinator effort (normalized by club size) for a given level of $E_{m}$ (Note 33). The curve's upward-sloping, convex shape is a consequence of the previously mentioned curvature conditions on $C(\cdot)$ and $n(\cdot)$. The tangency between the two curves is therefore a graphical representation of the coordinator's optimal mix of effort and fee levels, i.e., equation (10).

From Figure 2 we see that, all else equal, a lower variable cost associated with coordinator recruitment effort (e.g., due to a lower marginal cost) results in a larger $n^{c}$. Similarly, in communities where recruitment into the club is more (positively) responsive to coordinator effort and less (negatively) responsive to the membership fee, the family of membership isoquants will be more steeply sloped, implying that the tangency between the two curves will occur at a higher level of coordinator recruitment effort. This, in turn, implies that the tangent isoquant is defined over a larger $n^{c}$.

We note how these results would change in the event that the condition $\partial n / \partial E_{r}>0$ does not hold, i.e., $\partial n / \partial E_{r} \leq 0$ instead. In this case, the $n\left(E_{r}, F\right)=n^{c}$ curve's slope would be non-positive and the cost-minimizing tangency would occur at the origin, where $F=E_{r}=0$ and thus $n^{c}=0$, i.e., non-existence of the club. This makes sense intuitively, since under these conditions the club's budget would never balance at any level other than $E_{r}=0$.

Assuming a club equilibrium indeed exists, these types of issues - in particular, membership-size responsiveness to $E_{r}$ and $F$ - are important to consider when determining whether a conservation club has the potential, in a practical sense, to achieve the socially optimal expected water-shortage probability on behalf of the wider community. Perhaps more importantly is the question, to what extent must a club induce a conservation ethic among its membership (through the information/education effect) and/or deliver economies of scale (through the bulk-pricing 
effect) before an equilibrium exists where club members indeed attain the socially optimal level of conservation on behalf of the wider community? Further, how sensitive are these respective 'extents' to community size, in particular with respect to the club's size relative to the community's total population? To help answer these questions, we now turn to a numerical analysis of the problem.

\section{A Numerical Model of Conservation Clubs}

Without loss of generality, we initially assume our community is comprised of ten households, each with CobbDouglas preferences (Note 34),

$$
u_{i}=x_{i}^{\alpha_{i}} y_{i}^{\beta_{i}} \theta^{-\gamma_{i}} \quad i=1, \ldots, 10
$$

and $U=\sum_{i=1}^{10} u_{i}$. Further, the community's capacity gap is defined as,

$$
\theta=\frac{10 \phi}{\left(\sum_{i=1}^{10} y_{i}\right)}
$$

with constant $\phi>0$. As described in Section 2.3, households are classified along a continuum such that household 1 favors conservation the most among all households in the community (as embodied by the values of its utility parameters $\alpha_{1}, \beta_{1}$, and $\gamma_{1}$ relative to the other households), and household 10 favors conservation the least. Specific values for these and all other relevant parameters in the model are provided in Table 1 (Note 35). Note that for simplicity we assume a common $p_{i}=p$ across all households.

Table 1. Parameter values for simulations of initial equilibrium and Pareto efficient outcome.

\begin{tabular}{cc}
\hline Parameters & Values \\
\hline$\left\{\alpha_{1}, \ldots, \alpha_{10}\right\}$ & $\{0.52,0.54, \ldots, 0.7\}$ \\
$\left\{\beta_{1}, \ldots, \beta_{10}\right\}$ & $\{0.38,0.36, \ldots, 0.2\}$ \\
$\left\{\gamma_{1}, \ldots, \gamma_{10}\right\}$ & $\{0.15,0.14, \ldots, 0.06\}$ \\
$\left\{m_{1}, \ldots, m_{10}\right\}$ & $\{100,95, \ldots, 55\}$ \\
$\phi$ & 20 \\
$p$ & 2 \\
\hline
\end{tabular}

Applying conditions (1) and (2), which incorporate the assumption that $\theta$ is taken as given by each household in its maximization problem, we obtain the initial equilibrium solution to our model presented in Column 2 of Table 2 (Note 36). As expected, $y_{1}>\cdots>y_{10}$. The result $x_{1}>\cdots>x_{10}$ is driven by $m_{1}>\cdots>m_{10}$. Together, these results for $x_{i}$ and $y_{i}, i=1, \ldots, 10$, outweigh the marginal effects $\partial u_{1} / \partial \theta<\cdots<\partial u_{10} / \partial \theta<0$, resulting in $u_{1}>\cdots>u_{10}$.

Note. The Pareto efficient outcome is of course dependent upon ex post transfers of numeraire $x_{i}$ such that utilities of households $1-6$ are no lower than they were in the initial equilibrium. Such transfers are possible given the differences in aggregate utility levels across the initial equilibrium and the Pareto efficient outcome. 
Table 2. Results for initial equilibrium and Pareto efficient outcome (Note)

\begin{tabular}{lcc}
\hline Variables & Initial Equilibrium & Pareto Efficient Outcome \\
\hline$\left\{x_{1}, \ldots, x_{10}\right\}$ & $\{58,57,56,55,53,52,50,48,45,43\}$ & $\{12,14,18,24,31,42,58,80,115,168\}$ \\
$\left\{y_{1}, \ldots, y_{10}\right\}$ & $\{21,19,17,15,13,12,10,9,7,6\}$ & $\{6,6,7,9,10,13,16,20,25,32\}$ \\
$\left\{u_{1}, \ldots, u_{10}\right\}$ & $\{25,24,24,23,23,22,21,21,20,19\}$ & - \\
$\left\{W T P_{1}, \ldots, W T P_{10}\right\}$ & $\{1.74,1.54,1.36,1.18,1.02,0.87,0.73,0.61,0.49,0.38\}$ & 255 \\
$\sum_{i=1}^{10} u_{i}$ & 222 & 0.39 \\
$\theta$ & 0.55 &
\end{tabular}

Table 3. Utility parameters necessary for club to obtain efficient water-shortage probability.

\begin{tabular}{lcc}
\hline Utility Parameters & Original Values & New Values \\
\hline$\left\{\alpha_{1}, \ldots, \alpha_{5}\right\}$ & $\{0.52,0.54,0.56,0.58,0.6\}$ & $\{0.5,0.52,0.53,0.55,0.57\}$ \\
$\left\{\beta_{1}, \ldots, \beta_{5}\right\}$ & $\{0.38,0.36,0.34,0.32,0.3\}$ & $\{0.44,0.42,0.41,0.4,0.35\}$ \\
$\left\{\gamma_{1}, \ldots, \gamma_{5}\right\}$ & $\{0.15,0.14,0.13,0.12,0.11\}$ & $\{0.155,0.145,0.135,0.125,0.115\}$ \\
\hline
\end{tabular}

Results for the Pareto Efficient benchmark - presented in Column 3 of Table 2 - represent a major departure from the initial equilibrium in terms of the $x_{i}, y_{i}$, and $u_{i}$ rankings. Each of these rankings is reversed, reflecting the facts that for the benchmark problem (i) the individual household budget constraints are aggregated into a communitywide resource constraint, (ii) $\alpha_{1}<\cdots<\alpha_{10}$, and (iii) $\gamma_{1}>\cdots>\gamma_{10}$. As a result, it makes sense for the social planner to redistribute resources away from households $1,2,3, \ldots$ to households ....,8, 9, 10 in order to maximize aggregate utility (which occurs at 255 utils). In the process, the expected capacity gap is reduced from $55 \%$ to $39 \%$. Lastly, the set of $W T P_{i}$ values provided in Column 3 represent the respective households' willingness-to-pay for a reduction in $\theta$, from $\theta^{*}=55 \%$ to $\theta^{* *}=39 \%$.

To answer the central question posed in this section - to what extent must the coordinator induce a conservation ethic among the club's membership (through the information/education effect) and/or deliver economies of scale (through the bulk-pricing effect) in order to attain the socially optimal level of conservation in aggregate - we begin by making two underlying assumptions (Note 37). First, we assume that the membership fee is set such that $50 \%$ of the community's 10 households decide to join the club at the outset (i.e., households $1-5$ have become club members). Referring to the $W T P$ values provided in Table 2 , this means that $\$ 0.87<F \leq \$ 1.02$, which in turn implies that $C(\cdot)$ cannot exceed $\$ 5.10$ (or roughly $6.6 \%$ of median household income). Otherwise, the club's (short-run) budget-balance condition will be violated.

Second, we consider the two polar cases of (1) $E_{m}$ only affecting $p$ for households 1 - 5 (i.e., solely an economiesof-scale effect that reduces the price of member-household conservation effort from $p$ to $\left.p^{\prime}, i=1, \ldots, 5\right)$ and $(2)$ $E_{m}$ only affecting $\alpha_{i}, \beta_{i}$, and $\gamma_{i}, i=1, \ldots, 5$ (i.e., solely an information/education effect that changes the utility parameters of member households from $\alpha_{i}$ to $\alpha_{i}^{\prime}, \beta_{i}$ to $\beta_{i}^{\prime}$, and $\gamma_{i}$ to $\gamma_{i}^{\prime}$, respectively) (Note 38). Since by definition these two cases bound all possible intermediate cases, where $E_{m}$ affects both prices and the utility parameters, the results presented here should be considered boundary cases. In specific, the respective decreases in $p$ determined for Case 1 may be considered lower bounds on the decreases necessary to obtain the socially efficient capacity gap, $\theta^{* *}$. Likewise, the respective changes in $\alpha_{i}, \beta_{i}$, and $\gamma_{i}$ determined for Case 2 may be considered upper bounds on 
the changes necessary to obtain $\theta^{* *}$. With these two assumptions in hand we are able to answer the corresponding questions: how far must $p$ fall and to what extent must the utility parameters change for households $1-5$ before $\theta^{c}=\theta^{* *}$ ?

To answer the first question (Case 1), we reduce $p$ strictly for club members $i=1, \ldots, 5$, from its initial, given value of $\$ 2$ down to the value necessary for capacity gap $\theta^{c}$ to equal $\theta^{* *}(=0.39)$, while maintaining $p=2$ for non-members $i=6, \ldots, 10$. We find that the value of $p$ for club members $i=1, \ldots, 5$ such that $\theta^{c}=\theta^{* *}=0.39$ occurs at $\$ 1.77$, which represents an $11.5 \%$ decrease in price. In other words, assuming $50 \%$ of the community's households join the club, and the club coordinator is able to deliver an $11.5 \%$ decrease in the price of conservation flow to club members, this price decrease alone is sufficient to obtain the socially efficient level of conservation for the community at large.

With respect to Case 2, Table 3 presents new utility parameter values (for club members $i=1, \ldots .5$ ) that result in information/education having the same effect on the community's expected capacity gap as the $11.5 \%$ price decrease had in Case 1, i.e., the socially efficient conservation level is obtained (Note 39). We see that the change in $\beta_{i}$ is much larger, and the changes in $\alpha_{i}$ and $\gamma_{i}$ are much smaller (in percentage terms), than is the necessary decrease in the price of water conservation. On average (across the five club members), the necessary changes in $\alpha_{i}, \beta_{i}$, and $\gamma_{i}$ are $-4.6 \%, 19 \%, 4 \%$, respectively (Note 40). Thus, in this example, building a "conservation ethic" among member households that is strong enough to push the larger community to its socially efficient aggregate conservation level is not markedly different - in percentage terms - than effecting a decrease in the members' price of conservation flow.

Table 4. Sensitivity of equilibrium outcomes as relative size of club decreases (Part 1).

\begin{tabular}{cccccccccc}
\hline$C S$ & $\theta^{*}$ & $\theta^{* *}$ & $\theta^{*}-\theta^{* *}$ & $U^{*}$ & $U^{* *}$ & $U^{c}($ Case 1) & $U^{c}($ Case 2$)$ & $p^{c}$ & $\left\{W T P_{1}, \ldots, W T P_{5}\right\}$ \\
\hline $50 \%$ & 0.55 & 0.39 & 0.16 & 222 & 255 & 229 & 234 & 1.77 & $\{1.74,1.54,1.36,1.18,1.02\}$ \\
$33 \%$ & 0.73 & 0.58 & 0.15 & 322 & 360 & 331 & 320 & 1.71 & $\{1.55,1.38,1.21,1.06,0.91\}$ \\
$25 \%$ & 0.84 & 0.67 & 0.17 & 423 & 463 & 434 & 419 & 1.63 & $\{1.59,1.41,1.24,1.08,0.93\}$ \\
$20 \%$ & 0.92 & 0.73 & 0.19 & 522 & 566 & 538 & 519 & 1.55 & $\{1.64,1.46,1.28,1.12,0.97\}$ \\
\hline
\end{tabular}

To test the sensitivity of these results with respect to community size (or, alternatively, relative club size) - in particular, the extent to which the club members' respective conservation ethics must strengthen or $p$ must fall in order for the club to attain the socially optimal level of conservation on behalf of the wider community - we increase the size of the community from 10 to 25 in increments of five, i.e., we let the community grow in size from 10 to 15 to 20 to 25 members successively, while maintaining the club size at five members. In this way, the size of the club decreases relative to the community's overall population as the community's population grows in size. Specifically, relative club size (henceforth, $C S$ ) successively decreases from its original $50 \%$ of the community's population to $33 \%, 25 \%$, and finally $20 \%$. For this sensitivity analysis, each increment of five new non-member households simply replicates the parameter values for original non-member households $i=6, \ldots, 10$ in Table 1 . Simulation results for these new relative club sizes are presented in Tables 4 and 5, as well as Figure 3.

Several interesting patterns emerge in Table 4. To begin, the magnitude of the reduction in $\theta$ (going from $\theta^{*}$ to $\theta^{* *}$ ) as relative club size decreases from $C S=50 \%$ to $C S=20 \%$ first decreases from 0.16 for $C S=50 \%$ (given a "base value" of $\theta^{*}=0.55$ ) to 0.15 for $C S=33 \%$ (base value of $\theta^{*}=0.73$ ), in percentage terms a roughly $9 \%$ decrease. The magnitude of the reduction then increases from 0.15 for $C S=33 \%$ to 0.17 for $C S=25 \%$ (base value of $\theta^{*}=0.84$ ), in percentage terms a roughly $1 \%$ decrease. Finally, the magnitude of the reduction increases again from 0.17 for $C S=25 \%$ to 0.19 for $C S=20 \%$ (base value of $\theta^{*}=0.92$ ), in percentage terms a roughly $1 \%$ increase. We would expect the change in $\left(\theta^{*}-\theta^{* *}\right)$ to decrease monotonically as relative club size decreases because the types of households being added to the community's population in this exercise value conservation the least, meaning that, all else equal, the aggregate welfare gain associated with a decrease in the capacity gap from the initial to the socially efficient equilibrium should diminish as the community's population size increases. This would explain the decrease in $\left(\theta^{*}-\theta^{* *}\right)$ from $C S=50 \%$ to $C S=33 \%$. We are uncertain as to why this 
decreasing pattern in $\left(\theta^{*}-\theta^{* *}\right)$ is reversed as relative club size decreases from $C S=33 \%$ to $C S=20 \%$. One possible explanation could be that a relative-club-size threshold exists below which the "absolute effect" on the aggregate demand for conservation of increasing the number of non-member households (i.e., households with relatively low valuations of conservation flow and community water supply) outweighs the "relative effect" of a smaller relative club size.

Table 5. Sensitivity of equilibrium outcomes as relative size of club decreases (Part 2).

\begin{tabular}{cccc}
\hline$C S$ & $\left\{\alpha_{1}, \ldots, \alpha_{5}\right\}$ & $\left\{\beta_{1}, \ldots, \beta_{5}\right\}$ & $\left\{\gamma_{1}, \ldots, \gamma_{5}\right\}$ \\
\hline $50 \%$ & $\{0.5,0.52,0.53,0.55,0.57\}$ & $\{0.44,0.42,0.41,0.4,0.35\}$ & $\{0.155,0.145,0.135,0.125,0.115\}$ \\
$33 \%$ & $\{0.46,0.5,0.5,0.52,0.54\}$ & $\{0.44,0.42,0.41,0.4,0.35\}$ & $\{0.16,0.15,0.14,0.13,0.12\}$ \\
$25 \%$ & $\{0.44,0.48,0.48,0.5,0.52\}$ & $\{0.46,0.44,0.43,0.42,0.37\}$ & $\{0.165,0.155,0.145,0.135,0.125\}$ \\
& & &
\end{tabular}

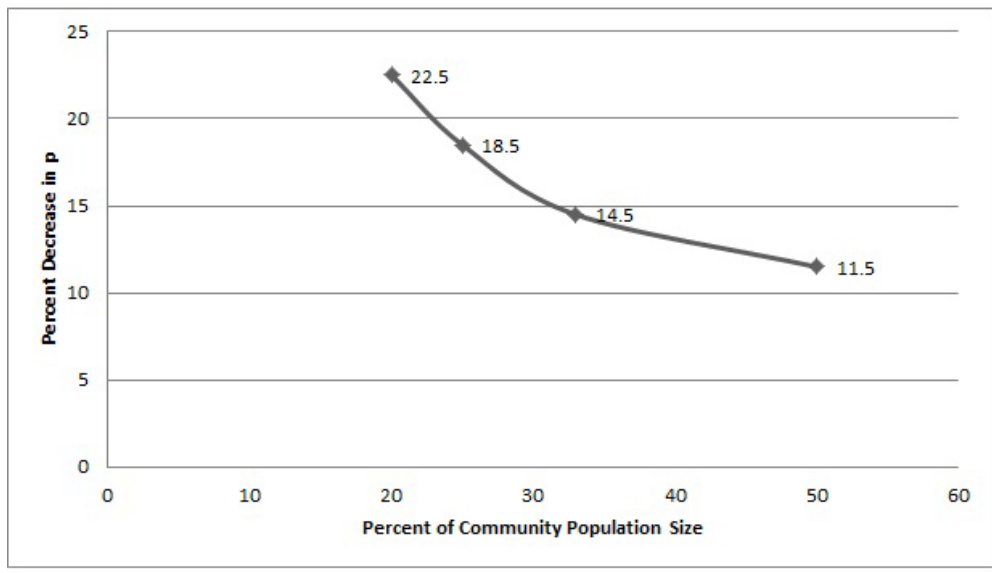

Figure 3. Club Equilibrium Changes in $p$ in relation to relative club size.

Nevertheless, these results for $\left(\theta^{*}-\theta^{* *}\right)$ impact the club members' respective $W T P$ values for reductions in $\theta$ in a predictable way. Given the specific form of preferences used in this simulation exercise, households' WT $P$ functions are such that $W T P$ is increasing and concave in $\left(\theta^{*}-\theta^{* *}\right)$. We would therefore expect to see the general pattern exhibited by the club members' respective $W T P$ values in our simulation exercise based on the pattern for $\left(\theta^{*}-\theta^{* *}\right)$. The values are higher for $C S=50 \%$ (where $\left(\theta^{*}-\theta^{* *}\right)=0.16$ ) than for $C S=33 \%$ (where $\left.\left(\theta^{*}-\theta^{* *}\right)=0.15\right)$. WT P values then increase sequentially as relative club size falls to $C S=25 \%$ and $C S=20 \%$ (in line with corresponding increases in $\left(\theta^{*}-\theta^{* *}\right)$ ). The determinants of the actual levels of the club members' respective $W T P$ values are, however, difficult to pin down as they are governed by three sometimes countervailing factors: (1) the value of $\left(\theta^{*}-\theta^{* *}\right),(2)$ the percentage change corresponding with this value, and (3) the starting value of $\theta^{*}$ itself.

The club members' $W T P$ values have an important implication for the feasibility of club formation as relative club size diminishes. For example, in moving from $C S=50 \%$ to $C S=33 \%$, the decrease in members' respective $W T P$ values implies that the coordinator will need to lower the membership fee, $F$, which in turn motivates the need to lower the costs associated with the coordinator's $E_{r}$ and $E_{m}$ in order to satisfy the budget-balance constraint. Because the $W T P$ values increase in moving from $C S=33 \%$ to $C S=20 \%$, this budget-balance issue becomes less pressing over this range of relative club size. 
Finally, as expected, the magnitude of the necessary decrease in the price of conservation flow (through bulkpricing) for club members to attain the socially efficient capacity gap decreases with relative club size. As relative club size increases, club members as a group shoulder a smaller burden relative to the community at large in attaining the socially efficient capacity gap. In turn, club members require smaller pricing discounts to increase their conservation efforts on behalf of the community. Figure 3 reveals that this negative relationship is convex.

In Table 5, we present various combinations of household utility parameter values (for the five club member households) that enable the community as a whole to attain the socially efficient capacity gap. Relative to the initial parameter values for the member households (see column 2 of Table 3), these new values represent an extent to which a "conservation ethic" would need to be instilled in the households by the club coordinator, all else equal. For point of reference, the initial parameter values are $\{0.52,0.54,0.56,0.58,0.6\}$ for $\alpha_{1}-\alpha_{5},\{.38,0.36,0.34,0.32,0.3\}$ for $\beta_{1}-\beta_{5}$, and $\{.15,0.14,0.13,0.12,0.11\}$ for $\gamma_{1}-\gamma_{5}$.

As indicated in Table 5, club members must strengthen their conservation ethics quite substantially in this example as relative club size decreases. For instance, in moving from a relative club size of $50 \%$ to a club size of $20 \%$ household 1's strengthened ethic entails a decrease in $\alpha_{1}$ from 0.5 to $0.42(16 \%)$, an increase in $\beta_{1}$ from 0.44 to $0.48(9 \%)$, and an increase in $\gamma_{1}$ from 0.155 to $0.18(16 \%)$. Similar parameter changes are required for households $2-5$.

\section{Summary and Conclusions}

This paper has examined how a "conservation club" might empower voluntary household-level conservation effort. Toward this end, we have characterized a socially optimal conservation benchmark and have derived the analytical conditions necessary for a club to attain this benchmark on behalf of the wider community. Theoretical analysis has demonstrated the ways in which households choose to become club members and are subsequently empowered to undertake aggressive conservation efforts. Numerical analysis has provided a first attempt at illustrating the extent to which a club must induce a conservation ethic among its membership (through the information/education effect) and/or deliver economies of scale (through a bulk-pricing effect) before the socially optimal conservation level is attained on a community level. The illustrations serve as examples of how the the necessary information/education and bulk-pricing effects can be measured, and show that the respective magnitudes of these effects are quite sensitive to the relative size of the club (relative to the community's population). We find that the relationship between the information/education and bulk-pricing effects, on the one hand, and relative club size, on the other, are highly non-linear, and in some cases non-monotonic. These results point to the need for a comprehensive empirical study, e.g., in the context of a multi-year field experiment.

Such an experiment could conceivably test the viability and effectiveness of a conservation club, or what Sofoulis and Williams (2008) call "meso-level" networking, in addition to other more-aggressive household-level interventions. One intervention might be a "contest," whereby a household essentially competes with itself to achieve targeted levels of water conservation during well-defined periods of time for a relatively substantial series of monetary rewards. For example, a household might be rewarded $\$ 1,000$ for obtaining a substantial conservation target during the year, and then maybe some fraction of this amount annually for maintaining that level of conservation during any remaining years of the experimental period. Researchers could then use an in-depth survey instrument to ascertain the specific behavioral changes and decision-making framework used by the household to achieve the conservation goal. This type of intra-household contest is necessary to get at how a household responds to significant monetary incentives because the alternative of enacting significant changes to its monthly pricing structure is, in a practical sense, infeasible (Note 41).

Another treatment might include intensive use of social media and networking to deliver more specific information to the household regarding its water usage relative to other households in the community, as well as more global information about alternative household-level water conservation strategies. The same type of information could be provided to those households in a "conservation club treatment", along with any bulk-pricing agreements arranged by the club coordinator with local retailers.

\section{Technical Appendix}

We begin by noting that the conservation-club equilibrium may be delineated according to two aggregated agents - club members $(\mathrm{m})$ and non-members $(\mathrm{nm})$ - which in turn necessitates some new definitions. First, we denote

$$
Y_{m}\left(E_{m}\right)=\sum_{i=1}^{n\left(E_{r}, F\right)} y_{i}^{*}\left(E_{m}\right)
$$


and

$$
Y_{n m}\left(E_{m}\right)=\sum_{i=n\left(E_{r}, F\right)+1}^{N} y_{i}\left(\theta\left(\sum_{i=1}^{n\left(E_{r}, F\right)} y_{i}^{*}\left(E_{m}\right)\right)\right) .
$$

In other words, the coordinator's $E_{m}$ directly affects aggregate club-member conservation flow, $Y_{m}\left(E_{m}\right)$, but affects aggregate non-member conservation flow, $Y_{n m}\left(E_{m}\right)$, only indirectly. Next, we denote the two reaction functions corresponding to $Y_{m}\left(E_{m}\right)$ and $Y_{n m}\left(E_{m}\right)$, respectively, as $Y_{m}\left(Y_{n m}\left(E_{m}\right)\right)$ and $Y_{n m}\left(Y_{m}\left(E_{m}\right)\right)$.

Figure 4 depicts a stylized version of the club equilibrium. The equilibrium determined by the intersection of the two downward-sloping reaction functions occurs in the face of both internal and external free-riding, while the equilibrium determined by the intersection of the downward-sloping $Y_{n m}\left(Y_{m}\left(E_{m}\right)\right)$ function with a (hashed) horizontal $Y_{m}\left(Y_{n m}\left(E_{m}\right)\right)$ function occurs in the absence of internal free-riding (Note 42). The assumption that $Y_{m}\left(Y_{n m}\left(E_{m}\right)\right)$ is the flatter of the two curves reflects the expected effectiveness of the club coordinator in mitigating the effects of internal free-riding. In the case a horizontal $Y_{m}\left(Y_{n m}\left(E_{m}\right)\right)$ curve, these effects are completely neutralized. In both cases, $Y_{m}^{c}+{Y_{n m}}^{c}=Y^{* *}$ in equilibrium via the capacity-gap constraint.

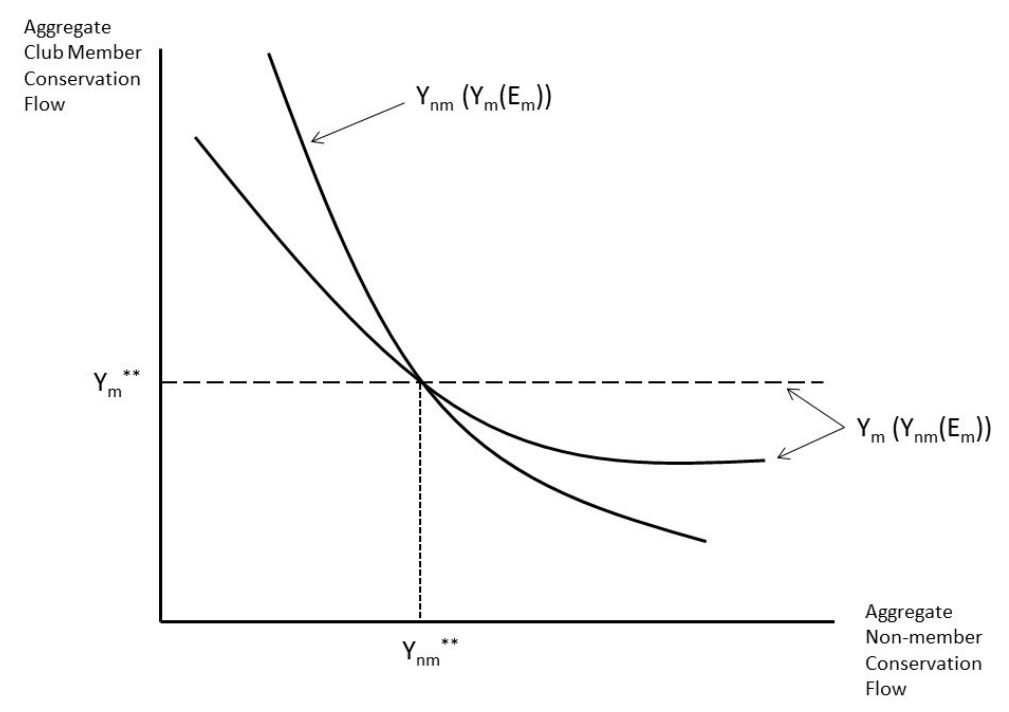

Figure 4. Club equilibrium reaction functions.

The necessary conditions for the existence of an interior equilibrium are that (1) the reaction functions are continuous, and (2) they cross at least once. Continuity is ensured via the assumption of convex preferences underlying the household's utility functions. Crossing is ensured via an application of the Intermediate Value Theorem when the flatter of the two curves has a lower vertical intercept than the steeper. Uniqueness (i.e., a single crossing) in the case of an impure public good is determined mathematically by a complex set of conditions described in Cornes and Sandler (1996) (Note 43). Lastly, Cornes and Sandler (1996) show that the equilibrium determined by the intersection of the reaction functions is locally stable when, in the case of the two downward-sloping reaction functions,

$$
\frac{\partial Y_{m}(\cdot)}{\partial Y_{n m}} \frac{\partial Y_{n m}(\cdot)}{\partial Y_{m}}<1
$$

which is as depicted in Figure 2 for both the downward-sloping and horizontal $Y_{m}\left(Y_{n m}\left(E_{m}\right)\right)$ curves.

\section{References}

Andreoni, J. (1990). Impure altruism and donations to public goods: a theory of warm-glow giving. The Economic Journal, 100(4), 464-477.

Baumann, D. D., Boland, J. J., \& Hanemann, W. M. (1998). Urban Water Demand Management and Planning. Mcgraw-Hill, New York. 
Billing, R. B., \& Day, W. M. (1989). Demand management factors in residential water use: the Southern Arizona experience. JAWWA, 81, 58-64.

Buchanan, J. M. (1965). An economic theory of clubs. Economica, 32, 1-14.

Campbell, H. E., Johnson, R. M., \& Larson, E. H. (2004). Prices, devices, people, or rules: the relative effectiveness of policy instruments in water conservation. Review of Policy Research, 21, 637-662.

Cornes, R., \& Sandler, T. (1996). The Theory of Externalities, Public Goods, and Club Goods. Cambridge University Press, Cambridge, UK.

Cropper, M. L., Jiang, Y., Alberini, A., \& Baur, P. (2014). Getting cars off the road: the cost-effectiveness of an episodic pollution control program. Environmental and Resource Economics, 57, 117-143.

Dalhuisen, J. M., Florax, R. J. G. M., de Groot, H. L. F, \& Nijcamp, P. (2003). Price and income elasticities of residential water demand: a meta analysis. Land Economics, 79, 292-308.

Espey, M., Espey, J., \& Shaw, W. D. (1997). Price elasticity of residential demand for water: a meta analysis. Water Resources Research, 33, 1369-1374.

Geller, S. E., Erickson, J. B., \& Buttram, B. A. (1983). Attempts to promote residential water conservation with educational, behavioural, and engineering strategies. Population Environment, 6, 96-112.

Hans, L. (2013). Are better informed consumers better? The effect of information in the context of household energy and water use. Unpublished manuscript, Department of Economics, Colorado State University.

Howarth, D., \& Butler, S. (2004). Communicating water conservation: how can the public be engaged. Water Supply, 4, 33-34.

Inman, D., \& Jeffrey, P. (2006). A review of residential water conservation tool performance and influences on implementation effectiveness. Urban Water Journal, 3(3), 127-143.

Laffont, J-J., \& Tirole, J. (1993). A Theory of Incentives in Procurement and Regulation. The MIT Press, Cambridge, MA.

Libecap, G. D. (1995). The conditions for successful collective action. In R. O. Keohane, \& E. Ostrom (Eds.), Local Commons and Global Interdependence: Heterogeneity and Cooperation in Two Domains (pp. 161190). SAGE Publications Ltd., London.

Linaweaver, F. P., Beebe, J. C., \& Skrivan, F. A. (1966). Data Report of the Residential Water Use Research Project, Baltimore, 1966. Department of Civil Engineering, Johns Hopkins University.

Maddaus, L. A. (2001). Effects of metering on residential water demand. MSc Thesis, UC Davis, California.

Mayer, P. W., Deoreo, W. B., \& Lewis, D. M. (2000). Seattle home water conservation study: the impacts of high efficiency indoor plumbing fixture retrofits in single-family homes. Submitted to the Seattle Public Utilities and USEPA by Aquacraft, Inc., Boulder, Colorado. Retrieved from the internet on January 10, 2010 at Www.aquacraft.com.

Mayer, P. W., Deoreo, W. B., Towler, E., \& Lewis, D. M. (2003). Residential indoor water conservation study: evaluation of high efficiency indoor plumbing fixture retrofits in single-family homes in the East Bay municipal utility district (EDMUD) service area. The United States Environmental Protection Agency, Washington, D.C. Retrieved from the internet on January 10, 2010 at www.aquacraft.com.

Mayer, P. W., Deoreo, W. B., Towler, E., Martin, L., \& Lewis, D. M. (2004). Tampa water department residential water conservation study: the impacts of high efficiency indoor plumbing fixture retrofits in single-family homes. Submitted to the Seattle Public Utilities and USEPA by Aquacraft, Inc., Boulder, Colorado. Retrieved January 10, 2010, from at www.aquacraft.com.

Mohadjer, J., \& Rice, D. L. (2004). Water Conservation Annual Report, 2004. Jordan Valley Conservancy District. Jordan Valley, Utah.

Natarja, S., \& Hanemann, W. M. (2008). Does marginal price matter? A regression discontinuity approach to estimating water demand. Department of Agricultural and Resource Economics, UCB. CUDARE Working Paper 1077.

Nieswiadomy, M. L. (1992). Estimating urban residential water demand: effects of price structure, conservation, 
and public education. Water Resources Research, 28, 609-615.

Olson, M. (1965). The Logic of Collective Action. Harvard University Press, Cambridge, Massachusetts.

Ostrom, E. (1998). A behavioral approach to the rational choice theory of collective action: Presidential address, American Political Science Association, 1997. The American Political Science Review, 92(1), 1-22.

Pal, R., \& Saha, B. (2014). Mixed duopoly and environment. Journal of Public Economic Theory, 16(1), 96-118.

Paldam, M. (2000). Social capital: one or many? definition and measurement. Journal of Economic Surveys, 14(5), 629-653.

Pint, E. M. (1999). Household responses to increased water rates during the California drought. Land Economics, 75(2), 246-266.

Renwick, M.E., \& Archibald, S.O. (1998). Demand-side management policies for residential water use: who bears the conservation burden? Land Economics, 74(3), 343-359.

Renwick, M. E., \& Green, R. D. (2000). Do residential demand-side management policies measure up? An analysis of eight California water agencies. Journal of Environmental Economics and Management, 40, 37-55.

Sandler, T., \& Tschirhart, J. (1997). Club theory: Thirty years later. Public Choice, 93, 335-355.

Sandler, T., \& Tschirhart, J.T. (1980). The economic theory of clubs: An evaluative survey. Journal of Economic Literature, 18(4), 1481-1521.

Scheld, A. M., Anderson, C. M., \& Uchida, H. (2012). The economic effects of catch share management: The Rhode Island fluke sector pilot program. Marine Resource Economics, 27(3), 203-228.

Sobel, J. (2002). Can we trust social capital? Journal of Economic Literature, 40(1), 139-154.

Sofoulis, Z., \& C. Williams (2008). From pushing atoms to growing networks: cultural innovation and co-evolution in urban water conservation. Social Alternatives, 27(3), 50-57.

Suzuki, K., Futagami, T., Ogura, S., Hara, M., Ohkawa, T., \& Yasui, I. (2004). Change in environmental consciousness and behavior led by information. Japan Science and Technology Agency, CREST Yasui Team. Retrieved March 28, 2015, from www.yasuienv.net/CREST/1list/1128.pdf.

Turner, A., White, S., Beatty, K., \& Gregory, A. (2004). Results of the Largest Residential Demand Management Program in Australia. Study Report, prepared by the Institute for Sustainable Futures. Sydney Water Corporation, Sydney Australia. Retrieved November 14, 2009, from www.isf.uts.edu.au/publications/turneretal2004largestresidentialde

USEPA (1998). Water Conservation Plan Guidelines. United States Environmental Protection Agency, Washington, DC. Retrieved January 10, 2010, from www.epa.gov/ow/waternews/1998/043098.html

Veld, K. V., \& Kotchen, M.J. (2011). Green clubs. Journal of Environmental Economics and Management, 62, 309-322.

Wang, Y., Song, J., Byrne, J., \& Yun, S. (1999). Evaluating the persistence of residential water conservation: a 1992-1997 panel study of a water utility program in Delaware. JAWWA, 35, 1269-1275.

\section{Notes}

Note 1. By "voluntary" we mean non-restrictive policies such as metering, changes in pricing structures, subsidies/rebates for purchase and retrofit of more efficient appliances/technologies, public education campaigns, etc. Alternatively, temporary resource-use restrictions and changes in building codes are examples of mandatory, or "coercive" policies.

Note 2. Nieswiadomy (1992) find that public education programs have a significantly larger effect in the western USA, which is more prone to water scarcity than the rest of the country. See Inman and Jeffrey (2006) for an overview these studies' findings, as well as the successive empirical findings discussed below.

Note 3. Hans (2013) provides an exhaustive review of the "limited information" literature, which addresses not only the empirical effects of smart metering on residential water and energy consumption, but also experimental evidence on a host of different feedback mechanisms.

Note 4. Renwick and Archibald (1998) are only able to do so with highly aggregated, cross-sectional categorical variables. Not all studies report such optimistic findings regarding the potential effects of retrofitting - see Mayer 
et al. (2003). Indeed, some studies find evidence of offsetting behavior (Geller et al., 1983; Campbell et al., 2004).

Note 5. See Dalhuisen et al. (2003) and Espey et al. (1997) for meta-analyses of the water-demand literature. Nataraj and Hanemann (2008) provide a novel approach to estimating marginal price effects based on a more dramatic pricing policy recently implemented in Santa Cruz, California.

Note 6. To the contrary, an exclusive club, as originally defined by Buchanan (1965), imposes size restrictions on membership in response to crowding effects, and produces the public good solely for its own members. See Cornes and Sandler (1996) and Sandler and Tschirhart $(1980,1997)$ for perspectives on the evolution of club theory, in particular the distinction between Olson's (1965) and Buchanan's (1965) notions of what constitutes a club. See Veld and Kotchen (2011) for a recent characterization of voluntary eco-certification programs as "green clubs." In the environmental psychology literature,"alternative consumption communities" (Shaw and Newholm, 2002; McDonald et al., 2006; Bekin et al., 2007) that can be created via "meso-level" networking strategies (Sofoulis and Williams, 2008) closely resemble the type of club we have in mind in this paper. Another example of the club we envision in this paper is provided by Scheld et al. (2012), who report on a catch share pilot program recently implemented by the Rhode Island Department of Environmental Management. The program divided the summer flounder, or "fluke" fishery into two groups: one smaller group consisting of eight members "known for being innovative and active in [sustainable] management and cooperative research within the state," and the other consisting of remainder of the fishing fleet. The goal of the program was to test the efficiency of the smaller, more innovative group in terms of meeting their independent total allowable catch through the use of transferable quotas. It is important to note that any environmental policy beset with non-compliancy creates by default - and admittedly by loose definition - what can be considered an Olson (1965)-esque club consisting of compliant agents. However, non-compliance rates are typically lower - and thus the "club" of compliant agents larger in a relative sense - than the relative club size we envision in this paper (see Cropper et al., 2014 for an empirical estimate of non-compliance with episodic air pollution regulations). Thus, in the context of non-compliance, the corresponding "compliancy club" would be larger in size (relative to the total population), as well as more decentralized in terms of sharing a common interest.

Note 7. In the case of water conservation, provision of information/education could include demonstrations of and discussions about retrofitting the most efficient appliances and technologies available in the global marketplace, smart metering, and water-wise gardening. Economies of scale would occur through bulk purchasing of these appliances and technologies.

Note 8 . The role of social networks in building "trust" or "social capital" among club members, e.g., in the context of managing common pool resources, has been a focal point of research in the fields of both game theory and experimental economics. For various perspectives on this literature see Libecap (1995), Ostrom (1998), Paldam (2000), and Sobel (2002).

Note 9. This notion of targeting households with stronger predispositions toward conservation is consistent with the empirical findings of Suzuki et al.(2004).

Note 10 . We therefore leave for future research the questions of whether a government authority should make an initial investment in establishing the club, how economies of scale might actually emerge through the club's purchasing decisions, and how spillover effects (i.e., the virtuous cycle mentioned above) might actually materialize. The answer to the question about government investment entails a weighing of the expected stream of (discounted) social benefits from the club's conservation efforts against the immediate costs associated with the club's establishment. And answers to the questions of emergent economies of scale and spillover effects entail estimating retail merchants' capacities to acquire, market, and service more-efficient technologies and appliances, and the extent of their market power in (global) wholesale markets for these goods.

Note 11 . The wording "conservation effort" and "conservation flow" are used interchangably throughout the remainder of the paper.

Note 12. By "capacity gap" we mean the difference between the community's capacity level (at which a water shortage is, on average, avoided) and the actual amount of water available for consumption. For water availability levels no less than capacity, the capacity gap is zero (which is equivalent to a zero probability of the community experiencing a water shortage during a given period).

Note 13. For expository convenience, we continue to refer to water as the resource being conserved. Energy conservation is complicated by the fact that if the energy being conserved produces a negative externality, such as air 
pollution through the burning of coal for electricity, then conservation reduces not only the probability of resource shortage, but also the effects of the externality. The model presented below can easily be adjusted to accommodate externalities of this nature. Nevertheless, our focus is restricted to the effects of conservation on the availability of the resource so as not to unnecessarily complicate the analysis.

Note 14. The model can conceivably accommodate households with negative marginal utility from consumption of $y_{i}$, i.e., $\partial u_{i} / \partial y_{i}<0$. In this case, we would assume that at least some households in the community exhibit nonnegative marginal utilities. Also, assuming $\theta$ enters the household's utility function as an exogenous parameter is admittedly restrictive. It implies that a household's motivations for choosing to conserve are (1) the "warm glow" it receives from the conservation flow itself (in cases where $\partial u_{i} / \partial y_{i}>0$ for $y_{i}>0$ ) and (2) any reduction in $p_{i}$ obtained through club membership. The household is therefore myopic and does not, on its own, make a connection between its conservation flow and a reduction in $\theta$. This assumption is perhaps more appropriate in the (very) small agent case, e.g., for highly populated communities. As discussed in Section 2.3, however, we do assume that when a household joins the club it learns about the specific effect that an increase in its $y_{i}$ has on the reduction in $\theta$. The notion that an individual obtains a warm glow through altruistic behavior is attributed to Andreoni (1990).

Note 15. The curvature conditions on $u_{i}$ also ensure second-order sufficiency conditions for maximization are satisfied for this and the Pareto efficiency problem in Section 2.2.

Note 16. As discussed in Section 2.3, club membership is also assumed to potentially induce changes in the household's utility parameters - to reflect the building of the household's conservation ethic. As a result, households may conceivably exhibit $W T P_{i}$ values for this change as well.

Note 17. We assume a fixed fee, rather than a variable fee based on club size, for ease of exposition and without loss of generality. Also, for future reference with respect to the analytics in Sections 2.2 and 2.3 we assume a large enough population of households such that they can be identified in a continuous sense.

Note 18. It would perhaps be more accurate to say that the household potentially joins the club when (3) holds, since at the time it formulates what we have assumed to be its certain $W T P$, the household does not know for sure whether joining the club will ultimately yield the changes in $\theta$ and $p_{i}$ being valued. The household therefore estimates its expected WTP instead, which, assuming risk-aversion, will be less than certain $W T P$. How much less depends upon both the magnitude of the anticipated changes in $\theta$ (i.e., $E_{i}\left(\theta^{\prime}-\theta\right)$ ) and $p_{i}$ (i.e., $E_{i}\left(p_{i}^{\prime}-p_{i}\right)$ ), where $E_{i}$ represents household $i$ 's expectation operator, and the household's perception of the coordinator's ability to deliver the changes. Thus, certain WTP can be thought of as an upper-bound on what the household's expected willingness to pay for club membership is likely to be.

Note 19. We say "a" rather than "the" solution in recognition of the fact that a set of Pareto-efficient solutions for this problem can be generated by altering the implicit weights on the $u_{i}$ in the maximand of the planner's objective function.

Note 20. Recall that in this model households themselves do not estimate the expected capacity gap or the extent to which their conservation efforts affect the gap. This estimation is made on the households' collective behalf by the regulator.

Note 21. These results hold for different values of price across the two problems as long as $p_{i}$ in the social planner's solution does not increase (relative to the value of $p_{i}$ in household's problem) by an amount large enough to offset the inequality

$$
\frac{\frac{\partial u_{i}\left(x_{i}^{*}, y_{i}^{*} ;\right)}{\partial y_{i}^{*}}}{\frac{\partial u_{i}\left(x_{i}^{*}, y_{i}^{*} ;\right)}{\partial x_{i}^{*}}}+\frac{\sum_{j=1}^{N}\left(\frac{\partial u_{j}\left(x_{i}^{* *}, y_{i}^{* *} ;\right)}{\partial \theta^{* *}} \frac{\partial \theta^{* *}}{\partial y_{i}^{* *}}\right)}{\frac{\partial u_{i}\left(x_{i}^{* *}, y_{i}^{* * ;} ;\right)}{\partial x_{i}^{* *}}}>p_{i}^{* *}, \quad i=1, \ldots, N
$$

where $p_{i}^{* *}$ represents the equilibrium price faced by the social planner.

Note 22. Under general demand and cost conditions, Pal and Saha (2014) show that in a mixed-duopoly setting (where one firm is fully private and the other at least partially public), it is optimal to tax firms' outputs at a lower rate than their abatement efforts are subsidized, while at the same time retaining full government ownership of the public firm. The lower tax rate reflects the need to compensate for a market power induced distortion that would otherwise encourage the private firm to reduce its output below the socially efficient level. As pointed out by an 
anonymous reviewer, in the context of our model any joint tax $\left(t_{i}\right)$-subsidy $\left(s_{i}\right)$ scheme satisfying the conditions

$$
t_{i}=\frac{\sum_{j=1}^{N}\left(\frac{\partial u_{j}}{\partial \theta} \frac{\partial \theta}{\partial y_{i}}\right)-s_{i} \frac{\partial u_{j}}{\partial x_{i}}}{\frac{\partial u_{i}}{\partial y_{i}}} \quad i, j=1, \ldots, N
$$

and

$$
\sum_{i=1}^{N}\left(s_{i}\left(y_{i}+\frac{x_{i} \frac{\partial u_{j}}{\partial x_{i}}}{\frac{\partial u_{j}}{\partial x_{i}}}\right)\right)=\sum_{i=1}^{N}\left(\frac{x_{i} \sum_{j=1}^{N}\left(\frac{\partial u_{j}}{\partial \theta} \frac{\partial \theta}{\partial y_{i}}\right)}{\frac{\partial u_{j}}{\partial y_{i}}}\right) \quad i, j=1, \ldots, N
$$

results in budget balance.

Note 23. The second assumption means that member-households learn to include the term $\frac{\frac{\partial u_{i}}{\partial \theta} \frac{\partial \theta}{\partial y_{i}}}{\frac{\partial u_{i}}{\partial x_{i}}}$ on the left-hand side of conditions (1).

Note 24. Condition $\partial^{2} n / \partial F^{2}<0$ would result if the distribution of $W T P$ follows a Cauchy sequence (in ascending order of $\left.W T P_{i}, i=1, \ldots, N\right)$.

Note 25. The coordinator therefore solves a cost-minimization problem that has no direct relationship with (i.e., is not the dual of) the Pareto efficient benchmark problem in Section 2.2). The coordinator?s problem has only an indirect relationship with the benchmark problem via the constraint that it attain the socially efficient water-shortage probability (or capacity gap) that was determined as part of benchmark?s solution. The two problems are distinct because the coordinator?s problem involves the coordinator choosing how to allocate effort between recruitment of new members and motivation of existing members in the most cost-effective way, taking into account how those efforts affect (1) both household WTP to join the club and existing members? own conservation efforts, respectively, (2) the club?s budget-balance condition, and (3) attainment of the wider community?s optimal capacity gap. Recall that the Pareto efficient benchmark problem involves a benevolent social planner choosing the levels of each respective household?s numeraire good and conservation effort directly subject to an economy-wide resource constraint. Thus, the benchmark solution targets what is fundamentally a community-wide problem, while the solution to the coordinator?s problem selectively targets club-member behavior.

Note 26. Recall that $y_{i}{ }^{*}$ refers to $i$ 's optimal demand for conservation flow derived in Section 2.1 for the now counterfactual case where the club did not yet exist.

Note 27. The incentive for free- (or, as they have named it, "easy-") riding, is explored at length in Cornes and Sandler (1996). Cornes and Sandler (1996) show that if a pure public good is normal and the real income effect is sufficiently strong, easy-riding may actually be negative, in the sense that an agent's contribution to the public good is increasing in the other agents' contributions, i.e., the Nash-Cournot reaction functions are upward sloping. In the case of an impure public good, such as the type modeled in this paper, Cornes and Sandler (1996) show that an upward-sloping reaction function is possible without appealing to income effects.

Note 28. External free-riding is also absent in the case of Cobb-Douglas preferences. Internal free-riding, however, is possible with Cobb-Douglas preferences as a result of member households learning the effects of their respective conservation efforts on $\theta$, i.e., learning their $\partial \theta / \partial y_{i}$ terms.

Note 29. The necessary and sufficient condition for club-member conservation effort to obtain the socially efficient capacity gap on behalf of the wider community (in the face of potential internal and external free-ridership) is provided below.

Note 30. Similar to the problems examined in Sections 2.1 and 2.2, the curvature conditions on $C\left(E_{r}, E_{m}\right)$ and $n\left(E_{r}, F\right)$ ensure second-order sufficiency conditions for minimization are satisfied for this problem.

Note 31. See Laffont and Tirole (1993), page 24, for a detailed explanation of the budget-balance constraint and its attendant multiplier.

Note 32. Since there are no production-type costs associated with the coordinator's choice of $F$, a term corresponding to the second term in condition (6) is absent in condition (8).

Note 33. As in Laffont and Tirole (1993), the $\lambda /(1+\lambda)$ term adjusts the coordinator's total cost curve to reflect the fact that the total cost of coordinator effort ultimately manifests itself as a need to raise public revenue, which in turn imposes a social, rather than private, cost. 
Note 34. These ten households can alternatively be thought of as representing households classified in each of the community's respective income or preference deciles. For simplicity, we assume the community's income and preference deciles contain the same households, i.e., those households with higher incomes also have stronger preferences for water conservation. We acknowledge the fact that because actual data with which to test the implications of the theoretical model presented in Section 2.3 are non-existent, we are precluded from drawing any empirical conclusions from our numerical analysis. We therefore consider our numerical results to be qualitative in nature.

Note 35. As indicated, $\alpha_{i}$ increases by the additive constant 0.02 , from 0.52 for household 1 to 0.6 for household 10. Likewise, $\beta_{i}$ decreases by additive constant 0.02 (from 0.38 to 0.2 ), and $\gamma_{i}$ decreases by additive constant 0.01 (from 0.15 to 0.06 ).

Note 36. Except for $W T P_{i}, i=1, \ldots, 10$, and $\theta$ (both of which are rounded to the second decimal point), solution values are rounded to the nearest integer. GAMS IDE 2.0.33.5 was used for this and all succeeding simulations. The input and output files for each simulation are available from the author upon request.

Note 37. We recognize that by imposing these assumptions our solution is illustrative rather than conclusive. Yet it is also important to recognize that the need for making these types of assumptions stems from the absence of empirical data that might otherwise provide conclusive evidence (in a statistical sense). Also, the assumptions can be altered in any manner to assess how the results presented below would accordingly change. We present a series of such alterations below.

Note 38. Recall that by joining the club a household also learns to account for the effect of its own conservation effort level on the community's expected capacity gap (as it affects its own utility, not that of the other households as in the social planner's problem). As a result, the member-household's first-order condition (1) becomes

$$
\frac{\frac{\partial u_{i}}{\partial y_{i}}+\frac{\partial u_{i}}{\partial \theta} \frac{\partial \theta}{\partial y_{i}}}{\frac{\partial u_{i}}{\partial x_{i}}}=p, \quad i=1, \ldots, 5
$$

where $p=p^{\prime}$ in Case 1 and $u_{i}$ is defined over parameters $\alpha_{i}^{\prime}, \beta_{i}^{\prime}$, and $\gamma_{i}^{\prime}$ in Case 2.

Note 39 . There are actually an infinite number of utility-parameter combinations capable of producing this result. The values presented in Table 3 represent only one such combination.

Note 40. We acknowledge that in a dynamic framework the socially efficient benchmark $\theta^{* *}$ would itself decrease concomitantly with the respective changes in the club members' respective utility parameters. We rule out this attendant 'moving target' problem, both in principle and by virtue of the static nature of our analysis.

Note 41. Based on the author's own personal experience, it is highly unlikely that a sufficient number of households can be recruited voluntarily into an experimental treatment that significantly alters their pricing structures (e.g., involving a relatively large increase in the price for higher "blocks" of water usage), let alone this type of treatment being sanctioned in the first place by the governmental authority responsible for billing the household.

Note 42. The two equilibria are drawn to occur at the same location purely for expository convenience.

Note 43. Cornes and Sandler (1996) show that uniqueness in a Nash-Cournot pure public goods equilibrium is guaranteed through normality of the public good.

\section{Copyrights}

Copyright for this article is retained by the author(s), with first publication rights granted to the journal.

This is an open-access article distributed under the terms and conditions of the Creative Commons Attribution license (http://creativecommons.org/licenses/by/4.0/). 